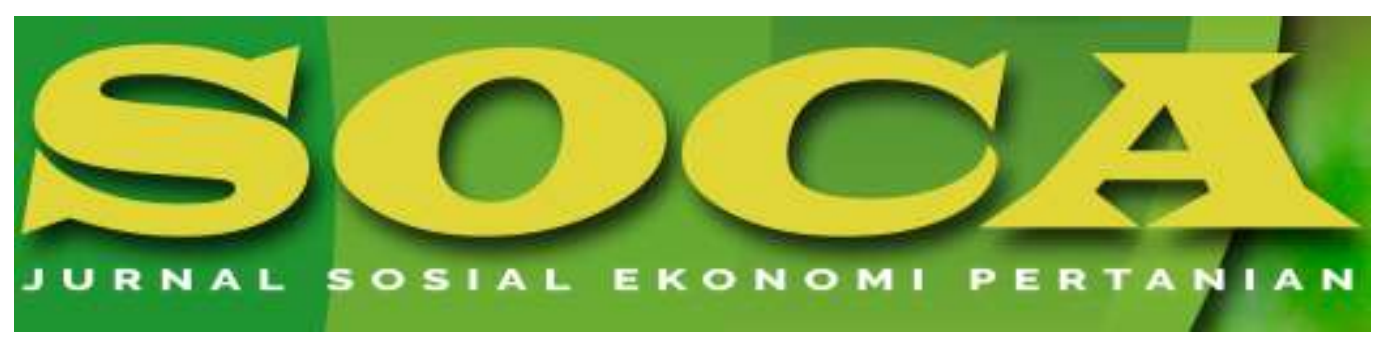

https://ojs.unud.ac.id/index.php/soca

\title{
ANALISIS KEBERLANJUTAN PROGRAM PENGENTASAN KEMISKINAN BERBASIS BANTUAN KOMODITAS AYAM DI NTB
}

I Putu Cakra Putra Adnyana, Tanda Panjaitan, Luh Gde Sri Astiti dan Awaludin Hipi Balai

Pengkajian Teknologi Pertanian (BPTP) Nusa Tenggara Barat

Email: Putucakra@yahoo.co.id,tanda_panjaitan@yahoo.com, luhde_astiti@yahoo.com. awlh@yahoo.co.id

Hp: 081915881663, 087821016711, 085239834020, 081337751378

\begin{tabular}{l}
\hline Keywords: \\
Kebijakan, \\
kemiskinan, \\
bantuan, \\
Ayam, NTB \\
\hline
\end{tabular}

\begin{abstract}
Program jangka menengah dalam pengentasan kemiskinan berbasis pertanian di Provinsi NTB memberikan 50 ekor ayam per rumah tangga miskin (RTM). RTM yang ikut program BEKERJA sebanyak 12.163 RTM berada di Kecamatan Praya Barat dan Timur. Tujuan pengkajian adalah opsi rekomendasi mendukung keberlanjutan pengentasan rumah tangga miskin berbasis bantuan komoditas ayam di NTB pasca program BEKERJA. Kegiatan tahun 2019 pada 6 desa di Kecamatan Praya Barat dan Timur Kabupaten Lombok Tengah Provinsi NTB. Data dikumpulkan melalui deskstudy, survey, FGD, ditabulasi kemudian dianalisis deskriptif, analisis stakeholder. Umumnya Program BEKERJA meningkatkan Kapasitas RTM dalam budidaya ayam KUB, meningkatkan gizi RTM melalui konsumsi telur dan daging ayam, terdapat peluang usaha ayam KUB.
\end{abstract}

\section{SUSTAINABILITY ANALYSIS OF POVERTY ALLEVIATION PROGRAM BASED ON CHICKEN COMMODITIES IN NTB}

\begin{tabular}{ll} 
ABSTRACT \\
Abstract \\
\hline \multicolumn{1}{c}{ Key } & The medium-term program in agriculture-based poverty \\
words: & alleviation in NTB Province provides 50 chickens per poor \\
Policy, & household (RTM). There were 12,163 RTM participating in the \\
poverty, & BEKERJA program in the West and East Praya Districts. The
\end{tabular}


assistance, purpose of the assessment is the recommendation option to Chicken, support the alleviation of poor households based on chicken NTB commodity assistance in NTB after the BEKERJA program. Activities in 2019 in 6 villages in West and East Praya Districts, Central Lombok District, NTB Province. Data collected through study, survey, FGD, tabulated then analyzed descriptively, stakeholder analysis. Generally the BEKERJA program increases RTM capacity in KUB chicken farming, improves RTM nutrition through the consumption of eggs and chicken meat, there are business opportunities for KUB chickens.

How to Cite (APA 6th Style):

Adnyana, I. P. C. P., Panjaitan, T., Astiti, L. G. S., \& Hipi, A. (2020). Analisis Keberlanjutan Program Pengentasan Kemiskinan Berbasis Bantuan Komoditas Ayam di NTB. SOCA: Jurnal Sosial Ekonomi Pertanian, 14(1), 88- 100.

https://doi.org/https://doi.org/ 10.24843/SOCA.2020.v14.i01.p08

\section{PENDAHULUAN}

Kementerian Pertanian meluncurkan gebrakan baru untuk mengentaskan kemiskinan berbasis pertanian. Gerakan ini ditargetkan dapat mengentaskan kemiskinan sebesar satu digit dari posisi saat ini, sesuai target untuk menurunkan angka kemiskinan dibawah 10 persen tahun 2018. Pemerintah melalui Kementerian Pertanian telah meluncurkan sebuah program guna mengentaskan kemiskinan yang disebut Program BEKERJA atau Bedah Kemiskinan Rakyat Sejahtera. Program ini menjangkau 1.000 desa di 100 kabupaten dan 10 provinsi, antara lain: Jawa Timur, Banten Sumatera Utara, Jawa Tengah, Jawa Barat, Sumatera Selatan, Lampung, Kalimantan Selatan, Sulawesi Selatan, dan Nusa Tenggara Barat (NTB). Jumlah RTM di Provinsi NTB yang memenuhi persyaratan menerima bantuan ayam 50 ekor per kepala keluarga sebanyak 12.163 RTM yang berada di dua kecamatan yaitu kecamatan praya barat dan praya Timur dengan masing-masing kecamatan sebanyak 10 desa.

Program Bedah Kemiskinan Rakyat Sejahtera (BEKERJA) berbasis pertanian yang diluncurkan oleh Kementerian Pertanian melalui Peraturan Menteri Pertanian No. 20/PERMENTAN/RC.120/5/2018 yang selanjutnya diubah melalui Peraturan Menteri Pertanian No. 27/PERMENTAN/ RC.120/5/2018 adalah upaya untuk pengentasan kemiskinan $\&$ pemberdayaan masyarakat miskin guna meningkatkan pendapatan dan kesejahteraan melalui kegiatan pertanian yang terintegrasi.

Terkait konsep distribusi bantuan, perlu juga memperhatikan konsistensi antara perencanaan di tingkat nasional sampai di daerah, serta juga memperhatikan keunggulan komparatif, ketepatan jumlah, waktu, dan sasaran sehingga perlu ditunjang oleh prosedur operasional di lapangan yang tepat. Namun sejauh mana efektifitas program ini dapat mengentaskan kemiskinan di 
NTB perlu dilakukan kajian analisis Analisis Keberlanjutan Program Pengentasan Kemiskinan Berbasis Bantuan Komoditas Ayam Di NTB dengan tujuan untuk mendapatkan opsi mendukung keberlanjutan pengentasan Rumah Tangga Miskin (RTM) berbasis bantuan komoditas ayam di NTB pasca program BEKERJA

\section{METODOLOGI PENELITIAN}

Ruang lingkup kegiatan ada di 12.163 rumah tangga miskin (RTM) yang berada di 20 desa di kecamatan praya barat dan praya timur. Kegiatan ini menggunakan pendekatan kebijakan keberlanjutan pasca program BEKERJA. Metode kegiatan dengan melakukan observasi, survey, deskstudy. Metode penentuan lokasi dilakukan secara random sampling dimana ditetapkan $30 \%$ dari 20 desa sehingga didapatkan sebanyak 6 desa, kemudian dari 6 desa ditetapkan lagi 30\% dari dusun yang ada di desa tersebut sehingga diperoleh 24 dusun, selanjutnya ditetapkan quota masing-masing dusun 4-5 RTM sehingga diperoleh 118 RTM. Data ditabulasi dan dianalisis dengan analisis deskriptif kualitatif dan kuantitatif serta analisis SWOT (Nasir, 1988).

\section{HASIL DAN PEMBAHASAN}

\section{Gambaran Umum Kecamatan Praya Timur dan Praya Barat}

Kecamatan Praya Timur dan Praya barat merupakan bagian dari dua belas kecamatan di Kabupaten Lombok Tengah. Adapun salah satu usaha ternak yang dikelola masyarakat adalah berasal dari peternakan unggas yaitu ayam, dimana tahun 2017 jumlah ayam kampung yang ada di praya timur sebanyak 108,112 ekor sedangkan ayam ras sebanyak 52,950 ekor, sedangkan Praya Barat sebanyak 328,223 ekor sedangkan ayam ras sebanyak 55,500 ekor (BPS Praya Barat, 2018); (BPS Praya Timur, 2018). Kabupaten Lombok Tengah penduduk miskin menurun dari 147,940 orang pada tahun 2015 menjadi 130,000 orang pada tahun 2018 (BPS Indonesia, 2019).

\section{Realisasi Program Bekerja}

Jumlah RTM penerima bantuan 12.163, Jumlah ayam terdistribusi 608,150 ekor (BAST). Kinerja Program Bekerja : 1). Populasi ayam per bulan Mei 2019 374,275 ekor (62.12\%), 2). Jumlah pakan terdistribusi 2018 sebesar 3,333,802 kg tahun 2019 sebesar 804, $600 \mathrm{~kg}$. Total sebesar 4,138,402 kg, 3). Jumlah obatobatan terdistribusi dengan nilai $\mathrm{Rp} 537,749,110$, 4. Jumlah vaksin yang terdistribusi dengan nilai Rp. 810.817.524, 4). Jumlah ayam yang mati 178,412 ekor $(29.34 \%)$, 5). Jumlah ayam dijual 35,925 ekor (5.91\%) dan dikonsumsi 19,538 ekor $(3.21 \%)$ 


\section{Mekanisme Pelaksanaan Kegiatan Bekerja}

Pemangku kepentingan adalah perorangan dan kelompok yang secara aktif terlibat dalam kegiatan, atau yang terkena dampak, baik positif maupun negatif, dari hasil pelaksanaan kegiatan. Secara garis besar, pemangku kepentingan dapat dibedakan atas tiga kelompok (Crosby 1992; Gonsalves et al. 2005), yaitu:1) Pemangku kepentingan utama, yakni yang menerima dampak positif atau negatif (diluar kerelaan) dari suatu kegiatan. 2) Pemangku kepentingan penunjang, adalah yang menjadi perantara dalam membantu proses penyampaian kegiatan. 3) Pemangku kepentingan kunci, yakni yang berpengaruh kuat terkait dengan masalah, kebutuhan, dan perhatian terhadap kelancaran kegiatan.

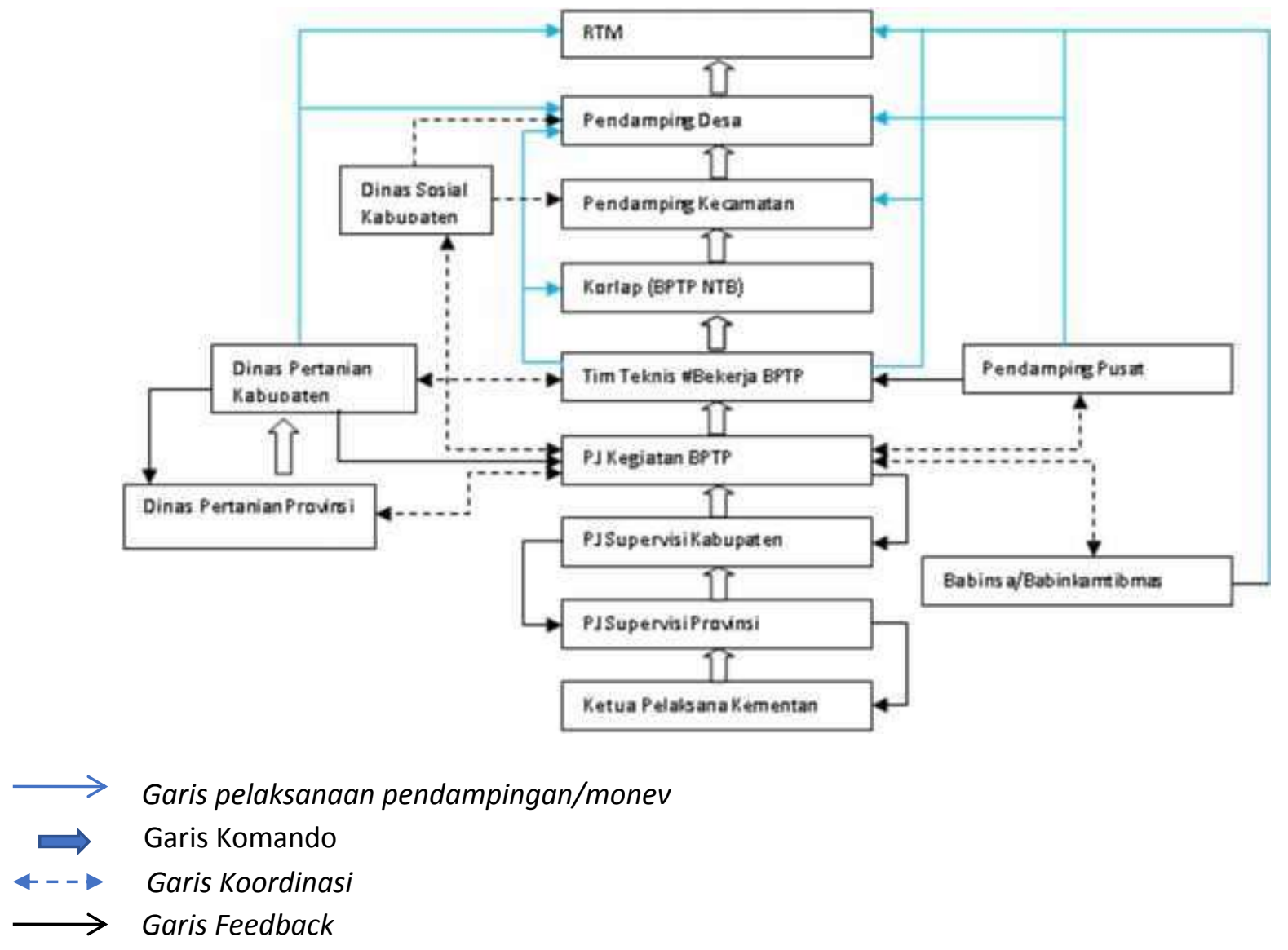

Gambar1. Mekanisme Pelaksanaan Kegiatan Bekerja

Sumber:data primer (diolah),2019

Berdasarkan mekanisme pelaksanaan Kegiatan BEKERJA, dapat dilihat banyaknya stakeholder yang terlibat untuk mendukung kegiatan BEKERJA mulai dari intansi pusat sampai instransi daerah. Semua stakeholder mempunyai fungsi dan tanggung jawab masing-masing untuk menjalankan Kegiatan BEKERJA. Jika ada salah satu stakeholder kurang aktif tentu akan menggangu kegiatan tersebut, sehingga perlu sinergitas antar inatansi/lembaga. 


\section{Ketersediaan sarana dan prasana pendukung program bekerja}

Analisis tingkat pelaksanaan kawasan program BEKERJA berdasarkan kondisi sarana dan prasarana penunjang. Analisis ini digunakan untuk menjelaskan ketersediaan sarana dan prasarana pada kawasan program BEKERJA di Kabupaten lombok Tengah. Mosher dalam Wahyu Widodo, (2010) berpendapat ada lima syarat yang harus dipenuhi agar pembangunan pertanian dapat tumbuhberkembang secara progresif, yaitu: (1) adanya pasar bagi produk-produk agribisnis, (2) teknologi yang senantiasa berubah, (3) tersedianya sarana dan peralatan produksi secara lokal, (4) adanya perangsang produksi bagi produsen, (5) adanya fasilitas transportasi. Dari hasil analisis tingkat ketersediaan sarana dan prasarana penunjang berdasarkan tabel 1 . hasil rekapitulasi maka tingkat ketersediaan untuk sarana penunjang di kategorikan sedang dengan nilai $55.65 \%$ dan sedangkan untuk tingkat ketersediaan prasarana dikategorikan tinggi dengan hasil rekapitulasi nilai $82.60 \%$.

Tabel 1. Sarana dan prasarana mendukung program BEKERJA Tahun 2019

\begin{tabular}{|c|c|c|c|}
\hline No. & $\begin{array}{c}\text { Sarana \& prasarana mendukung program } \\
\text { BEKERJA }\end{array}$ & $\begin{array}{l}\text { Jml RTM } \\
\text { Tahu (\%) }\end{array}$ & Nilai (\%) \\
\hline \multicolumn{4}{|c|}{ Sarana program BEKERJA } \\
\hline$\exists$ & Lembaga penyuluhan/UPTD & 7.63 & 60.00 \\
\hline כ & Lembaga riset/pengkajian/penelitian & 3.39 & 54.17 \\
\hline c & Bumdes & 17.80 & 63.54 \\
\hline $\mathrm{d}$ & Bank / bank pasar/koperasi & 39.83 & 55.21 \\
\hline e & Distributor/pedagang DOC & 22.03 & 35.46 \\
\hline $\mathrm{f}$ & Toko pakan, obat-obatan & 67.80 & 65.42 \\
\hline $\mathrm{g}$ & Pedagang ayam & 66.95 & 58.54 \\
\hline 1 & Restoran/Warung makan & 59.32 & 50.00 \\
\hline $\mathrm{i}$ & Toko peralatan utk ayam & 56.78 & 60.42 \\
\hline \multirow[t]{2}{*}{ j) } & Pasar tradisional, Rumah potong ayam & 71.19 & 53.75 \\
\hline & Rata-rata & 41.27 & 55.65 \\
\hline \multicolumn{4}{|c|}{ 2. Prasarana program BEKERJA } \\
\hline a & Jaringan Listrik & 92.37 & 85.63 \\
\hline כ & Jaringan jalan & 91.53 & 80.21 \\
\hline c & Jaringan Air bersih & 91.53 & 80.00 \\
\hline \multirow[t]{2}{*}{$\mathrm{x}$} & Jaringan komunikasi & 83.90 & 84.58 \\
\hline & Rata-rata & 89.83 & 82.60 \\
\hline
\end{tabular}

Sumber: Diolah dari data primer (2019)

Keterangan

a. Kategori tinggi, (Sudah Terencana dan Sudah Terealisasi) diberi nilai 5 ( jika $80 \%-100 \%$ tingkat ketersediaan sarana dan prasarana)

b. Kategori sedang (Sudah Terencana Tapi Belum Terealisasi) diberi nilai 3 (jika $50 \%-79 \%$ tingkat ketersediaan sarana dan prasarana)

c. Kategori rendah diberi nilai 1 (Belum Terencana dan Belum Terealisasi)jika (jika $<50 \%$ tingkat ketersediaan sarana dan prasarana) 
Berdasarkan tabel 1 didapatkan data bahwa RTM sebagian besar tidak mengetahui dimana bisa mendapatkan DOC ayam KUB, disamping itu juga beberapa RTM tidak mengetahui dimana bisa membeli input usaha ternak ayam KUB seperti pakan, obat-obatan dan peralatan lainnya. RTM juga tidak tahu dimana lembaga penyuluhan dan lembaga riset sehingga mempengaruhi kemudahan dalam mengakses informasi teknologi usaha ternak ayam KUB. Sehingga hal ini dapat berpengaruh negative terhadap keberlanjutan dari program BEKERJA.

\section{Pelaksanaan Program Bekerja}

Secara tipologi, Pretty (1995) mengklasifikasikan partisipasi atas tujuh karakteristik yaitu ; Pasif, informasi, konsultasi, insentif material, fungsional, interaktif, mobilisasi swadaya. Dari ketujuh karakteristik tersebut, partisipasi interaktif merupakan jenis partisipasi pemangku kepentingan yang dianggap paling sesuai dengan implementasi program pembangunan pertanian. Berdasarkan tingkat kedalaman, Hussein (2000) membedakan partisipasi menjadi partisipasi bersifat dangkal dan partisipasi mendalam. Perbedaan antara keduanya antara lain terletak pada esensi, kegiatan, dan tujuannya.

Proses pembelajaran dan keterlibatan pemangku kepentingan dalam implementasi program pembangunan pertanian meliputi: 1) persiapan (identifikasi dan pemaduan pemangku kepentingan, identifikasi kerangka kerja dalam hal pengembangan informasi, pemahaman terhadap pengeloladan pengguna sumber daya, dan pemilihan opsi kegiatan), 2) implementasi (andil, penggunaan, dan stimulasi pengetahuan), dan 3) evaluasi terhadap proses dan perolehan hasil pelaksanaan program pembangunan pertanian (Arthur dan Garaway 2005).

Penyuluhan ayam KUB berperan menghubungkan lembaga ilmiah sebagai sumber hal baru dengan Rumah Tangga Miskin (RTM) sebagai yang membutuhkan. Hubungan ini harus dilanjutkan dengan bimbingan teknis (BIMTEK) untuk menumbuhkan keyakinan dan keinginan mencobanya sendiri. Kegiatan menyampaikan sesuatu yang baru yang lebih baik, menguntungkan kepada RTM, dengan tujuan meningkatkan kemauan dan kemampuan RTM dalam berusaha ayam KUB.

Pada umumnya responden paham terhadap materi palatihan/BIMTEK, namun ada reponden yang tidak paham hal ini salah satunya disebabkan adanya kendala bahasa lokal dalam BIMTEK sehingga informasi tidak diterima utuh. Beberapa RTM tidak mengetahui secara pasti sumber informasi berasal dari instansi mana sehingga kesulitan untuk mengakses informasi secara langsung dan cepat bilamana kegiatan BEKERJA sudah tidak berlanjut. Selama program BEKERJA Pendamping desa sering melakukan kunjungan ke RTM untuk melakukan penyuluhan terkait ayam KUB, serta menghubungkan dengan sumber informasi seperti peneliti BPTP NTB dengan RTM sebagai pengguna informasi.

Berdasarkan tabel 2. persepsi responden pada Teknologi Introduksi Usaha Ternak Ayam KUB didapatkan hasil bahwa responden /RTM masuk kategori sedang, artinya memiliki potensi untuk diadopsi oleh RTM tapi masih ragu-ragu. Namun untuk komponen teknologi kandang penghangat DOC dan kesehatan ayam KUB dengan menjaga kebersihan pada lingkungan kandang RTM mempunyai 
persepsi yang baik sehingga 2 teknologi tersebut bisa diadopsi secara berkelanjutan

Tabel 2. Persepsi Responden Pada Teknologi Introduksi Tahun 2019

\begin{tabular}{|c|c|c|c|c|c|c|}
\hline Teknologi Introduksi & $\begin{array}{l}\text { Ting } \\
\text { kat } \\
\text { Peng } \\
\text { etah } \\
\text { uan }\end{array}$ & $\begin{array}{c}\text { Kema } \\
\text { mpua } \\
\text { n } \\
\text { untuk } \\
\text { dicoba }\end{array}$ & $\begin{array}{l}\text { Ting } \\
\text { kat } \\
\text { kes } \\
\text { ulit } \\
\text { an }\end{array}$ & $\begin{array}{c}\text { Kesesu } \\
\text { aian } \\
\text { dengan } \\
\text { kebiasa } \\
\text { an RTM }\end{array}$ & $\begin{array}{l}\text { Keunggu } \\
\text { lan } \\
\text { relatif }\end{array}$ & $\begin{array}{l}\text { Rat } \\
\text { a- } \\
\text { rat } \\
\text { a }\end{array}$ \\
\hline \multicolumn{7}{|l|}{ Kandang } \\
\hline 1. Kandang penghangat DOC & 3 & 3 & 3 & 2 & 3 & 3 \\
\hline $\begin{array}{l}\text { 2. Kandang pembesaran } \\
\text { Kapasitas kandang umur 45- } \\
60 \text { hari }=20-22 \text { ekor } / \mathrm{m} 2\end{array}$ & 2 & 2 & 2 & 2 & 2 & 2 \\
\hline \multicolumn{7}{|l|}{ Pemeliharan ayam KUB } \\
\hline $\begin{array}{l}\text { 1. Mengatasi kanibalisme pada } \\
\text { ayam KUB }\end{array}$ & 2 & 2 & 2 & 1 & 2 & 2 \\
\hline $\begin{array}{l}\text { 2. Pemberian pakan \& minum } \\
\text { untuk DOC }\end{array}$ & 3 & 3 & 3 & 2 & 2 & 2 \\
\hline $\begin{array}{l}\text { 3. Kebutuhan pakan komersial } \\
\text { ayam KUB dewasa }\end{array}$ & 2 & 2 & 1 & 1 & 2 & 2 \\
\hline \multicolumn{7}{|l|}{ Kesehatan ayam KUB } \\
\hline 1. Vaksinasi ayam KUB & 2 & 1 & 1 & 1 & 1 & 1 \\
\hline $\begin{array}{l}\text { 2. Tindakan menjaga kebersihan } \\
\text { pada lingkungan kandang }\end{array}$ & 3 & 3 & 3 & 2 & 3 & 3 \\
\hline \multicolumn{7}{|l|}{ Penyakit Ayam } \\
\hline 1. Penanganan ayam sakit & 2 & 2 & 2 & 1 & 2 & 2 \\
\hline Rata-rata & 2 & 2 & 2 & 2 & 2 & 2 \\
\hline
\end{tabular}

Sumber: Diolah dari data primer (2019)

Keterangan

*) Isikan tanda $(\sqrt{ })$ pada kolom yang sesuai:

1) tingkat pengetahuan: $1=$ tidak tahu; $2=$ ragu-ragu; $3=$ tahu

2) Kemampuan untuk dicoba: 1 kurang mampu; $2=$ ragu-ragu; $3=$ mampu

3) Tingkat kesulitan: $1=$ sulit; $2=$ ragu-ragu; 3= mudah

4) Kesesuaian dengan kebiasaan RTM: 1= kurang sesuai; $2=$ ragu-ragu; $3=$ sesuai

5) Keunggulan relatif (keuntugan/manfaat): $1=$ Kurang untung; 2= ragu-ragu; $3=$ untung

Usaha ayam KUB memiliki potensi sebagai sumber penghasilan baru, walau hasilnya (daging dan telur) masih untuk memenuhi kebutuhan dasar konsumsi RTM sendiri. RTM mengunakan hasil penjualan untuk kebutuhan dasar RTM seperti sandang, pangan dan kesehatan.

Usaha ayam KUB dilakukan di lingkungan padat penduduk, namun sebagian besar masyarakat sekitar tidak terganggu dengan bau kotoran yang dikeluarkan dari ayam KUB, karena kandang selalu dibersihkan. Pengendalian 
Berdasarkan tabel 3. Diperoleh data responden yang mampu mengakses input usaha ternak ayam sebanyak 38,98\% setelah program BEKERJA selesai. Sedangkan untuk input DOC dan peralatan ternyata RTM tidak memiliki akses informasinya.

Tabel 4. Aksesibilitas Responden terhadap pemasaran hasil ayam KUB Tahun 2019

\begin{tabular}{lcc}
\hline \multicolumn{1}{c}{ Uraian } & Telur & Ayam KUB \\
\hline Tujuan pemasaran hasil panen 1) & 1 dan 4 & 1 dan 4 \\
\hline $\begin{array}{l}\text { Jumlah lembaga pemasaran hasil yang biasa } \\
\text { dihubungi RTM (orang) }\end{array}$ & 2 & 2 \\
\hline Kemudahan memasarkan hasil panen 2) & 1 & 1 \\
\hline $\begin{array}{l}\text { Ikatan bisnis (kemitraan/ pinjam uang/ pinjam input) } \\
\text { antara RTM dengan lembaga tersebut 2) }\end{array}$ & 2 & 2 \\
\hline Cara penjualan hasil 3) & 3 & 3 \\
\hline Cara pembayarannya 4) & 1 & 1 \\
\hline
\end{tabular}

Sumber: Diolah dari data primer (2019)

Keterangan

1) Isikan : 1=konsumen desa; $2=$ konsumen kecamatan/kabupaten; 3 =supermarket; 4=pedagang pengumpul desa; 5=pedagang kecamatan; $6=$ industri pengolahan; $7=$ mitra usaha

2) Isikan : 1=ya; $2=$ tidak

3) Isikan : 1=ijon (dijual borongan sebelum umur panen); 2=tebasan (dijual borongan setelah umur panen); 3=per unit hasil (kg, kwt, butir, dst)

4) Isikan : 1=tunai; 2=bayar dimuka; $3=$ bayar kemudian setelah terjual

Berdasarkan tabel 4. aksesibilitas responden terhadap pemasaran hasil ayam KUB didapatkan hasil bahwa pada umumnya pemasaran telur dan ayam KUB ditujukan ke konsumen desa dan pedagang pengumpil desa, dimana hanya $15,25 \%$ responden yang menjual telurnya sedangkan $51,69 \%$ reponden yang menjual ayam KUB. Sisanya dikonsumsi sendiri atau tidak mati.

\section{Respon RTM setelah menerima informasi teknologi ayam KUB}

Berdasarkan tabel 5. Respon RTM setelah menerima informasi teknologi ayam KUB didapatkan hasil bahwa respon RTM berbeda-beda namun sebagian besar RTM mendiskusikan dengan keluarga dan dan masyarakat lainnya, dan hanya 50\% yang menerapkan sesuai anjuran, yang menarik hanya $27,97 \%$ yang beroreantasi pasar.

Tabel 5. Respon RTM setelah menerima informasi teknologi ayam KUB Tahun 2019

\begin{tabular}{lrc}
\hline \multicolumn{1}{c}{ Tindakan yang dilakukan } & \multicolumn{2}{c}{$\mathrm{RTM}$} \\
\cline { 2 - 3 } & $\mathrm{Jml}$ & $\%$ \\
\hline Mengkaji kinerja teknologi (kritis) & 27 & 22.88 \\
\hline Mencari informasi lebih banyak & 49 & 41.53 \\
\hline
\end{tabular}




\begin{tabular}{lll}
\hline $\begin{array}{l}\text { Menerapkan teknologi dengan mendiskusikan } \\
\text { dengan keluarga }\end{array}$ & 68 & 57.63 \\
\hline $\begin{array}{l}\text { Menerapkan teknologi dengan mendiskusikan } \\
\text { dengan masyarakat lainnya }\end{array}$ & 51 & 43.22 \\
\hline Menerapkan sesuai anjuran sumber informasi & 59 & 50.00 \\
\hline Berani mengambil resiko kegagalan & 42 & 35.59 \\
\hline Menyebar luaskan kepada masyarakat lainnya & 37 & 31.36 \\
\hline $\begin{array}{l}\text { Menerapkan teknologi dengan tidak dipengaruhi } \\
\text { oleh pendapat dan kegiatan mayarakat sekitar. }\end{array}$ & 49 & 41.53 \\
\hline Menerapkan teknologi berdasarkan orientasi pasar & 33 & 27.97 \\
\hline
\end{tabular}

Sumber: Diolah dari data primer (2019)

\section{Analisis SWOT}

Analisis SWOT digunakan sebagai alat formulasi strategi yaitu dengan mengidentifikasi berbagai faktor secara sistematis untuk merumuskan strategi pemerintah dalam menjaga keberlanjutan suatu program. (Rangkuti, 2011). Analisis SWOT membandingkan antara faktor eksternal dan internal kegiatan program BEKERJA.

Tabel 6. Analisis SWOT Kegiatan BEKERJA Tahun 2019

\begin{tabular}{|c|c|c|}
\hline & KEKUATAN (S) & KELEMAHAN (W) \\
\hline $\begin{array}{l}\text { FAKTOR INTERNAL } \\
\text { DAN EKSTERNAL }\end{array}$ & $\begin{array}{l}\text { 1. Keterlibatan } \\
\text { stakeholder/instan } \\
\text { si terkait } \\
\text { 2. Kemampuan } \\
\text { pengelolaan usaha } \\
\text { Ayam KUB oleh } \\
\text { RTM sebagai } \\
\text { sumber } \\
\text { penghasilan baru } \\
\text { 3. Aksesibilitas } \\
\text { RESPONDEN } \\
\text { terhadap } \\
\text { pemasaran hasil } \\
\text { ayam KUB }\end{array}$ & $\begin{array}{l}\text { 1. Pendidikan RTM rendah } \\
\text { 2. Pendidikan Pendamping } \\
\text { Desa tidak semua } \\
\text { berlatar belakang } \\
\text { peternakan } \\
\text { 3. Pengetahuan RTM } \\
\text { tentang ketersediaan } \\
\text { Sarana dan Prasana } \\
\text { Pendukung program } \\
\text { bekerja rendah } \\
\text { 4. Persepsi RTM Pada } \\
\text { Teknologi Introduksi } \\
\text { 5. Peran bahasa lokal } \\
\text { dalam penyebaran } \\
\text { teknologi Ayam KUB } \\
\text { 6. Kapasitas RTM dalam } \\
\text { mengelola limbah dari } \\
\text { kotoran ayam } \\
\text { 7. Kemampuan RTM untuk } \\
\text { mengakses sumber } \\
\text { permodalan untuk } \\
\text { mengembangkan usaha } \\
\text { Ayam KUB } \\
\text { 8. Aksesibilitas }\end{array}$ \\
\hline
\end{tabular}




\begin{tabular}{|c|c|c|}
\hline & & $\begin{array}{l}\text { RESPONDEN terhadap } \\
\text { input usaha ternak } \\
\text { ayam setelah program } \\
\text { BEKERJA selesai }\end{array}$ \\
\hline PELUANG (O) & Strategi SO & Strategi WO \\
\hline $\begin{array}{l}\text { 1. Tingkat } \\
\text { ketersediaan } \\
\text { sarana } \\
\text { pendukung } \\
\text { Kegiatan Bekerja } \\
\text { (lembaga } \\
\text { penyuluhan, } \\
\text { keungan, } \\
\text { BUMDES, riset, } \\
\text { pasar, distributor) } \\
\text { Tingkat } \\
\text { ketersediaan } \\
\text { Prasarana } \\
\text { pendukung } \\
\text { kegiatan Bekerja } \\
\text { (listrik, jalan, air } \\
\text { komunikasi) }\end{array}$ & $\begin{array}{l}\text { 1. Perlu dukungan } \\
\text { kelembagaan } \\
\text { keuangan lainnya } \\
\text { seperti BUMDES, } \\
\text { Bank, Koperasi } \\
\text { dalam } \\
\text { mengembangkan } \\
\text { usaha ternak ayam } \\
\text { KUB. } \\
\text { 2. Peningkatan } \\
\text { informasi dan } \\
\text { aksesibiltas RTM } \\
\text { terhadap } \\
\text { pemasaran melalui } \\
\text { dukungan dan } \\
\text { peran aktif } \\
\text { stakeholder/instan } \\
\text { si terkait }\end{array}$ & $\begin{array}{l}\text { 1. Peningkatan } \\
\text { pengetahuan RTM } \\
\text { terhadap informasi dan } \\
\text { aksesibilitas } \\
\text { ketersediaan sarana } \\
\text { prasarana melalui } \\
\text { pertemuan kelompok, } \\
\text { workshop, atau melalui } \\
\text { media dan metode } \\
\text { diseminasi lainnya } \\
\text { 2. Memanfaatkan } \\
\text { ketersediaan sarana dan } \\
\text { prasarana pendukung } \\
\text { untuk mendukung } \\
\text { program Bekerja }\end{array}$ \\
\hline
\end{tabular}

\section{ANCAMAN (T)}

1. Tingginya tingkat kematian ayam

KUB akibat penyakit dan manajemen pemeliharaan ayam KUB

2. Dukungan keamanan Lingkungan terhadap program Bekerja

3. Persaingan produsen DOC dari luar NTB, tingkat efisensi pembibitan scala kecil rendah sehingga tidak
Strategi ST

1. Pengembangan kelembagaan pembibitan ayam KUB pola kemitraan intiplasma sudah dirintis tahun 2019

2. Membangun ketahanan sistem sosial untuk mengurangi gangguan keamanan

3. Manajemen pemeliharaan ayam KUB sesuai SOP
Strategi WT

1. Dukungan pemerintah yang terintegrasi untuk peningkatan kapasitas peternak dalam pemeliharaan ayam kampung

2. Peningkatan kapasitas pendamping melalui bimbingan teknis

3. Diperlukan suatu program pendampingan teknologi pemeliharaan ayam KUB secara berkelanjutan 
mampu bersaing

Sumber: Diolah dari data primer (2019)

Dari hasil analisis SWOT dengan rumusan tersebut diperoleh berbagai strategi yang dapat dilakukan untuk keberlanjutan usaha ayam KUB di Lombok Tengah. Strategi tersebut dapat dibagi menjadi dua strategi besar yaitu strategi yang berhubungan dengan kegiatan teknis dan strategi yang berhubungan dengan kegiatan sosial-kelembagaan.

\section{KESIMPULAN}

Kegiatan program BEKERJA secara keseluruhan bermanfaat meningkatkan Kapasitas RTM meningkat untuk budidaya ayam KUB, Peningkatan gizi RTM melalui konsumsi telur dan daging ayam, serta terdapat peluang usaha ternak ayam KUB.

\section{SARAN}

1. Rekomendasi teknis

a. Peningkatan pengetahuan peternak terhadap informasi ketersediaan sarana prasarana melalui pertemuan kelompok, workshop, atau melalui media dan metode diseminasi lainnya

b. Dukungan pemerintah secara terintegrasi untuk peningkatan kapasitas peternak dalam pemeliharaan ayam kampung

c. Peningkatan kapasitas pendamping melalui bimbingan teknis

d. Diperlukan suatu program pendampingan teknologi pemeliharaan ayam KUB secara berkelanjutan

2. Rekomendasi Sosial Kelembagaan

a. Perlu dukungan kelembagaan keuangan lainnya seperti BUMDES, Bank, Koperasi dalam mengembangkan usaha ternak ayam KUB.

b. Peningkatan informasi dan aksesibiltas RTM terhadap pemasaran melalui dukungan dan peran aktif stakeholder/instansi terkait

c. Memanfaatkan ketersediaan sarana dan prasarana pendukung untuk mendukung program Bekerja

d. Pengembangan kelembagaan pembibitan ayam KUB pola kemitraan intiplasma sudah dirintis tahun 2019

e. Membangun ketahanan sistem sosial untuk mengurangi gangguan keamanan

\section{DAFTAR PUSTAKA}

Arthur, R.I. and C.J. Garaway. 2005. Learning in action: A case from small waterbody fisheries in Lao PDR. In J. Gonsalves, T. Becker, A. Braun, D. Campilon, H. de Chaves, E. Fajber, M. Capiriri, J.R. Caminade, and R. Vernooy (Eds.) Participatory Research and Development for Sustainable 
Agricultural and Natural Resource Management: A Resource Book. International Potato Center-Users Perspective with Agricultural Research and Development, Philippines.

BPS Indonesia 2019. https://www.bps.go.id/dynamictable/2017/08/03/ 1260/jumlah-penduduk-miskin-menurut-kabupaten-kota-2015---2018.html

BPS, Praya barat 2018. Kecamatan Dalam angka. Lombok Tengah

BPS, Praya Timur 2018. Kecamatan Dalam angka. Lombok tengah

Crosby, B.L. 1992. Stakeholder Analysis: A vital tool for strategic managers. Technical Notes, No. 2. Agency for International Development, Washington DC.

Gonsalves, J., T. Becker, A. Braun, D. Campilon, H. de Chaves, E. Fajber, M. Capiriri, J.R. Caminade, and R. Vernooy. 2005. Participatory Research and Development for Sustainable Agricultural and Natural Resource Management: A resource book (glossary). International Potato Center-Users Perspective with Agricultural Research and Development, Philippines.

Hussein, K. 2000. Monitoring and Evaluating Impact on Livelihoods: Lessons from experience. Department for International Development, United Kingdom.

Nazir. 1988. Metode Penelitian. Ghalia Indonesia Jakarta.

Pretty, J. 1995. Regenerating Agriculture: Policies and practice for sustainability and selfreliance. Earthscan Publications, London.

Rangkuti, Freddy, 2011. SWOT Balanced Scorecard. Teknik Menyusun strategi Korporat yang efektif plus cara mengelola kinerja resiko. PT Gramedia Pustaka Utama. Jakarta. 